\title{
Honokiol alleviates sepsis-induced acute kidney injury in mice by targeting the miR- 218-5p/heme oxygenase-1 signaling pathway
}

Tao Zhang ${ }^{1 * \dagger}$ and Lei Xiang ${ }^{2+}$

\author{
* Correspondence: zhang_taohh@ \\ 163.com \\ ${ }^{\dagger}$ Tao Zhang and Lei Xiang \\ contributed equally. \\ ${ }^{1}$ Department of of Intensive Care \\ Unit, Tianjin Huanhu Hospital, No. 6 \\ Jizhao Road, Tianjin 300060, \\ People's Republic of China \\ Full list of author information is \\ available at the end of the article
}

\begin{abstract}
Background: Honokiol is a low-molecular-weight natural product and has been reported to exhibit anti-inflammatory activity.

Objectives: Our study aimed to investigate the influence of honokiol on sepsisinduced acute kidney injury (AKI) in a mouse model.

Material and methods: A cecal ligation and puncture (CLP) surgical operation was performed to establish a sepsis-induced acute kidney injury model in mice. Renal histomorphological analysis was performed with periodic acid-Schiff (PAS) staining. The levels of inflammatory markers in serum were measured by ELISA assay. The mRNA and protein levels were assayed by RT-qPCR and western blotting, respectively. Annexin V-FITC/PI staining was used to evaluate glomerular mesangial cell (GMC) apoptosis.

Results: The results revealed that honokiol significantly increased the survival rate in mice undergoing a CLP operation. Inflammatory cytokines, such as TNF-a, IL- 6 and IL$1 \beta$, were significantly inhibited in honokiol-treated septic mice compared with the CLP group. In addition, honokiol showed the ability to reverse CLP-induced AKI in septic mice. Furthermore, heme oxygenase-1 ( $\mathrm{HO}-1)$ expression levels were significantly upregulated and miR-218-5p was markedly down-regulated in honokiol-treated septic mice as compared to CLP-operated mice. Bioinformatics and experimental measurements showed that HO-1 was a direct target of miR-218-5p. In vitro experiments showed that both honokiol and miR-218-5p inhibitors blocked lipopolysaccharide (LPS)-induced cell growth inhibition and GMC apoptosis by increasing the expression of $\mathrm{HO}-1$.
\end{abstract}

Conclusions: Honokiol ameliorated AKI in septic mice and LPS-induced GMC dysfunction, and the underlying mechanism was mediated, at least partially, through the regulation of miR-218-5p/HO-1 signaling.

Keywords: Honokiol, Sepsis, Acute kidney injury, Heme oxygenase-1

\section{Introduction}

Sepsis is caused by infections with bacteria such as Staphylococcus aureus and is characterized by a whole-body inflammatory response, which is a leading cause of death in intensive care units (ICUs) [1]. There have been an increasing number of studies

(c) The Author(s). 2019 Open Access This article is distributed under the terms of the Creative Commons Attribution 4.0 International License (http://creativecommons.org/licenses/by/4.0/), which permits unrestricted use, distribution, and reproduction in any medium, provided you give appropriate credit to the original author(s) and the source, provide a link to the Creative Commons license, and indicate if changes were made. The Creative Commons Public Domain Dedication waiver (http://creativecommons.org/ publicdomain/zero/1.0/) applies to the data made available in this article, unless otherwise stated. 
showing that acute kidney injury (AKI) is a frequent and serious complication of sepsis in ICU patients, accounting for $50 \%$ or more of cases of AKI in ICUs, and is associated with a very high mortality [2]. In clinical practice, there are approximately 1000,000 reported cases and more than 160,000 deaths each year attributable to sepsis in the United States alone [3]. Although inflammatory reaction triggered by cytokine production is a leading cause of sepsis-induced multiple organ system failure, little progress has been made in the management of sepsis. Therefore, it is important to explore a novel and effective adjuvant therapy drug for sepsis-induced organ failure.

Honokiol is a low-molecular-weight natural product isolated and purified from Magnolia officinalis, which has been shown to participate in a variety of physiological and pathological processes $[4,5]$. Previous studies have demonstrated that honokiol alleviates experimental mesangial proliferative glomerulonephritis [6] and inhibits LPS- and high-glucose-induced upregulation of inflammatory cytokines in human renal mesangial cells (HRMCs) [7, 8]. Moreover, honokiol ameliorates renal fibrosis by inhibiting extracellular matrix and pro-inflammatory factors in vivo and in vitro [9]. Honokiol protects against renal ischemia/reperfusion injury via the suppression of oxidative stress and inflammatory reactions in a rat model [10]. Interestingly, honokiol ameliorates sepsis-associated acute lung injury [5] and kidney injury [11] in murine models via the inhibition of oxidative stress and inflammation. However, the underlying molecular mechanisms of sepsis-induced AKI and the protective effect of honokiol in sepsis-induced organ failure have not been clearly delineated.

Heme oxygenase-1 (HO-1) as an inducible enzyme plays a crucial role in anti-oxidation, anti-inflammation, anti-apoptosis and cytoprotection [12]. Extensive evidence has demonstrated that $\mathrm{HO}-1$ has a protective effect against AKI in various animal models, such as sepsis-, ischemia-reperfusion- and kidney transplantation-induced AKI [13-15]. HO-1 knockout exhibits enhancement of the inflammatory response and structural renal injury $[16,17]$. In human renal epithelial cells, overexpression of HO-1 inhibits reactive oxygen species generation, autophagy and apoptosis and promotes cell survival during hypoxia and oxidative stress $[18,19]$.

MicroRNAs (miRNAs) have been revealed as small, single-stranded and non-coding RNAs that contribute to post-transcriptional regulatory mechanisms and regulate gene expression by binding to the 3 '-untranslated regions (3'-UTRs) [20]. MiRNAs have been shown to be involved in a variety of biological processes, including sepsis-induced AKI. For example, miR-107, miR-124, miR-204 and miR-590 are mediators of sepsis-induced AKI for their ability to specifically bind to 3'-UTRs to inhibit translation of the target genes [21, 22]. In the present study, we aimed to investigate the role of miR-218-5p and its target gene HO-1 in sepsis-induced AKI and hypothesized that honokiol could ameliorate sepsis-induced AKI by targeting the miR-218-5p/HO-1 signaling pathway. This study will further increase our understanding of the renoprotective effect of honokiol, which may be useful in managing sepsis-induced renal failure.

\section{Materials and methods}

\section{Experimental animals}

Ten-week-old male ICR mice ( $n=80$; body weight: $20-25 \mathrm{~g}$ ) were obtained from Vital

River Laboratories Co., Ltd. (Beijing, China) and allowed to acclimatize to the 
environment for 1 week. The mice were fed under controlled conditions - temperature $25 \pm 2{ }^{\circ} \mathrm{C}$, humidity $55 \pm 5 \%$ and 12 -h light/dark cycle - and the mice were given free access to food and tap water. Sepsis was induced in mice undergoing cecal ligation and puncture (CLP) surgery as previously described [23]. Honokiol (Aldrich Chemical Co., Milwaukee, WI, USA; high performance liquid chromatography, 98\%; formula: $\mathrm{C}_{18} \mathrm{H}_{18} \mathrm{O}_{2}$ ) dissolved in dimethyl sulfoxide (DMSO) was intraperitoneally injected into CLP-induced septic mice at the concentration of $2.5 \mathrm{mg} / \mathrm{kg}$ (low dose, $n=10$ ) or 10 $\mathrm{mg} / \mathrm{kg}$ (high dose, $\mathrm{n}=10$ ) body weight after CLP treatment twice within $24 \mathrm{~h}$. The mice in the control group were intraperitoneally injected with $2 \mathrm{ml}$ of PBS. In another experiment, the $96 \mathrm{~h}$ survival of CLP mice with or without honokiol treatment was observed ( $n=10$ in each group). The study was approved by the Ethics Committee of Tianjin Huanhu Hospital, Tianjin, China.

\section{Bacterial counts in blood and organs}

Twenty-four hours after the CLP operation, the mice were killed, and the blood, kidney, liver and brain were collected and homogenized in $2 \mathrm{ml}$ of sterile PBS. After serial dilution, the homogenates and the blood were spread on LB agar plates and incubated at $37^{\circ} \mathrm{C}$ for $24 \mathrm{~h}$. Colonies were counted and expressed as CFU/organ.

\section{Serum inflammatory cytokines}

Twenty-four hours after CLP operation, blood was collected and centrifuged, and the levels of tumor necrosis factor- $\alpha$ (TNF- $\alpha$; cat. no. E-EL-M0049), interleukin (IL)- $1 \beta$ (cat. no. E-EL-M0037) and IL-6 (cat. no. E-EL-M0044) in serum were detected using a mouse bioactive ELISA assay, according to the manufacturer's protocol (Elabscience Biotechnology Co., Ltd., Wuhan, China).

\section{Histomorphology and immunohistochemistry}

Formalin-fixed and paraffin-embedded kidney tissues were cut into about $4 \mu \mathrm{m}$-thick sections, which were stained with periodic acid-Schiff (PAS) staining (Abcam, Cambridge, UK), and visualized under a microscope (Leica DM 2500; Leica Microsystems GmbH, Wetzlar, Germany).

\section{Cell culture}

Mouse glomerular mesangial cells (GMCs; serial number: 3131C0001000300021) were obtained from the Institute of Biochemistry and Cell Biology of the Chinese Academy of Sciences (Shanghai, China). Cells were cultured in Dulbecco's modified Eagle's medium-F12 (DMEM-F12; Gibco; Thermo Fisher Scientific, Inc., Waltham, MA, USA) with $5 \%$ fetal bovine serum (Beyotime Institute of Biotechnology, Haimen, China), $2 \mathrm{mM}_{\mathrm{L}}$-glutamine, $100 \mathrm{U} / \mathrm{ml}$ penicillin and $100 \mathrm{mg} / \mathrm{ml}$ streptomycin in a humidified incubator (Thermo Fisher Scientific, Inc.), $5 \% \mathrm{CO}_{2}, 95 \%$ air atmosphere. Lipopolysaccharide (LPS; $10 \mu \mathrm{g} / \mathrm{mL}$; Sigma-Aldrich, Merck KgaA, Germany) was exposed to GMCs with or without honokiol treatment at various concentrations $(0,1,10,100$ and $200 \mu \mathrm{M})$. 


\section{Luciferase reporter assay}

The conserved binding sites between miR-218-5p and HO-1 were obtained using the online predict software TargetScan (http://www.targetscan.org) and miRDB (http:// www.mirdb.org/miRDB/). miR-Con, miR-218-5p mimics and inhibitors were synthesized by RiboBio (Guangzhou, China). GMCs were seeded in 6-well plates and transfected with miR-Con, miR-218-5p mimics and inhibitors using Lipofectamine 2000 (Invitrogen; Thermo Fisher Scientific, Inc., Waltham, MA, USA) for $48 \mathrm{~h}$ at $37^{\circ} \mathrm{C}$ according to the manufacturer's protocol. The wild-type (WT) and mutant-type (MT) 3 '-UTR of HO-1 were inserted into the multiple cloning sites of the luciferase expressing PMIR-REPORT vector (Ambion; Thermo Fisher Scientific, Inc.). For the luciferase assay, GMCs $\left(1 \times 10^{5}\right)$ were seeded into 24-well plates and co-transfected with luciferase reporter vectors containing the WT or MT 3'-UTR of HO-1 $(0.5 \mu \mathrm{g})$ and mimic sequences of miR-218-5p (100 nM) using Lipofectamine 2000 (Invitrogen; Thermo Fisher Scientific, Inc.). The luciferase activity was measured using a luciferase reporter assay kit (Promega, Madison, WI, USA) according to the manufacturer's protocol.

\section{Cell viability}

After treatment with different conditions for 24,48 or $72 \mathrm{~h}$, cell viability was measured using the CCK-8 Cell Proliferation/Viability Assay Kit (Dojindo, Japan). Absorbance was recorded at $450 \mathrm{~nm}$ using an Elx800 Reader (Bio-Tek Instruments Inc., Winooski, VT, USA).

\section{Cell apoptosis}

After treatment with different conditions for $48 \mathrm{~h}$, an Annexin V-FITC/PI kit (Becton, Dickinson and Company, New Jersey, USA) was used to stain cells for $15 \mathrm{~min}$, and then a cell apoptosis assay was performed by flow cytometry assay (FACScan, BD Biosciences, San Jose, CA, USA) and analyzed by CELL Quest 3.0 software (BD Biosciences).

\section{Reverse transcription-quantitative polymerase chain reaction (RT-qPCR) miRNA RT-qPCR}

Total RNA was extracted from kidney using TRIzol (Invitrogen; Thermo Fisher Scientific, Inc., USA). RT was performed using a TaqMan reverse transcription kit (Applied Biosystems; Thermo Fisher Scientific, Inc.), according to the manufacturer's protocol. MiRNAs were detected using a TaqMan MicroRNA assay (Applied Biosystems; Thermo Fisher Scientific, Inc.), according to the manufacturer's protocol. U6 small nuclear RNA was used as an endogenous control. Relative miRNA expression levels were calculated using the $2^{-\Delta \Delta C q}$ method [24]. The primers of miRNAs are shown in Additional file 1: Table S1.

\section{IRNA RT-qPCR}

The cDNA was synthesized by reverse transcription reactions with $2 \mu \mathrm{g}$ of total RNA using Moloney murine leukemia virus reverse transcriptase (Invitrogen; Thermo Fisher Scientific, Inc.) according to the manufacturer's protocol. RT-qPCR was performed by the Applied Biosystems 7300 Real-Time PCR System (Thermo Fisher Scientific, Inc.) with the TaqMan Universal PCR Master Mix (Thermo Fisher Scientific, Inc.). Glyceraldehyde 
3-phosphate dehydrogenase (GAPDH) served as an internal standard. Relative gene expression was calculated using the $2^{-\triangle \Delta C q}$ method [24]. PCR was performed with the following primers: Bcl-2, forward 5'-CCAGCGTGTGTGTGCAAGTGTAAAT-3' and reverse 5'-ATGTCAATCCGTAGGAATCCCAACC-3'; BAX, forward 5'-CAGGGTTTC ATCCAGGATCGAGCAGG-3' and reverse 5' -CGGGGGGAGTCCGTGTCCACGTCA G-3'. HO-1, forward 5'-CAGCCCCACCAAGTTCAAAC-3' and reverse 5'-GTCT TTGTGTTCCTCCTCTGTCAGCAT-3'; GAPDH, forward 5'-GCACCGTCAAGCTG AGAAC-3' and reverse 5' -TGGTGAAGACGCCAGTGGA-3'.

\section{Western blotting}

Protein was extracted from kidneys using NP-40 buffer (Thermo Fisher Scientific, Inc.), followed by $5-10 \mathrm{~min}$ boiling and centrifugation at $10,000 \mathrm{~g}$, for $10 \mathrm{~min}$ at $4{ }^{\circ} \mathrm{C}$ to obtain the supernatant and was quantified using the Bicinchoninic Acid kit for Protein Determination (no. BCA1-1KT; Sigma-Aldrich; Merck Millipore). Samples containing $30 \mu \mathrm{g}$ of proteins were separated by $10 \%$ SDS-PAGE and transferred to nitrocellulose membranes (Bio-Rad Laboratories, Inc., Hercules, CA, USA). Membranes were blocked for $2 \mathrm{~h}$ at room temperature with $5 \%(w / v)$ non-fat dry milk in tris-buffered saline and $0.1 \%(\mathrm{w} / \mathrm{v})$ Tween 20 (TBST), and then incubated with primary antibodies specific for HO-1 (cat. no. sc-1796, 1: 1000; Santa Cruz Biotechnology, Inc., Dallas, TX, USA). $\beta$-actin (cat. no. sc-81,178; dilution, 1: 2000; Santa Cruz Biotechnology) was used as a protein loading control. The membranes were next incubated with the appropriate HRP (horseradish peroxidase)-conjugated antibody (cat. no. sc-516,102; 1:10,000; Santa Cruz Biotechnology) at room temperature for $2 \mathrm{~h}$. Signal detection was carried out with an enhanced chemiluminescence system (GE Healthcare, Chicago, IL, USA), and protein bands were analyzed with Quantity One software version 4.5 (Bio-Rad Laboratories, Inc., Hercules, CA, USA).

\section{Statistical analysis}

The data from these experiments were reported as mean \pm SEM for each group. All statistical analyses were performed using PRISM version 7.0 (GraphPad Software, Inc., La Jolla, CA, USA). Student's $t$-test was used to analyze two-group differences. Inter-group differences were analyzed by one-way analysis of variance, followed by a post hoc Tukey test for multiple comparisons. A $P$ value less than 0.05 was considered to indicate a statistically significant difference.

\section{Results}

\section{Honokiol improves survival in mice after S. aureus or CLP treatment}

To determine the functional roles of honokiol in sepsis in mice, honokiol $(2.5 \mathrm{mg} / \mathrm{kg}$ or $10 \mathrm{mg} / \mathrm{kg}$ ) was administered to mice $30 \mathrm{~min}$ after CLP treatment. The survival of these mice was monitored for 4 days after the induction of sepsis by the CLP operation. The results demonstrated that both low-concentration and high-concentration honokiol significantly increased the survival in mice undergoing CLP as compared to mice only treated with CLP (Fig. 1). Sepsis was induced in mice by CLP; the survival rates in CLP, $\mathrm{L}+\mathrm{CLP}$ and $\mathrm{H}+\mathrm{CLP}$ groups were 10,40 , and $60 \%$, respectively, after 4 days of treatment (Fig. 1). 


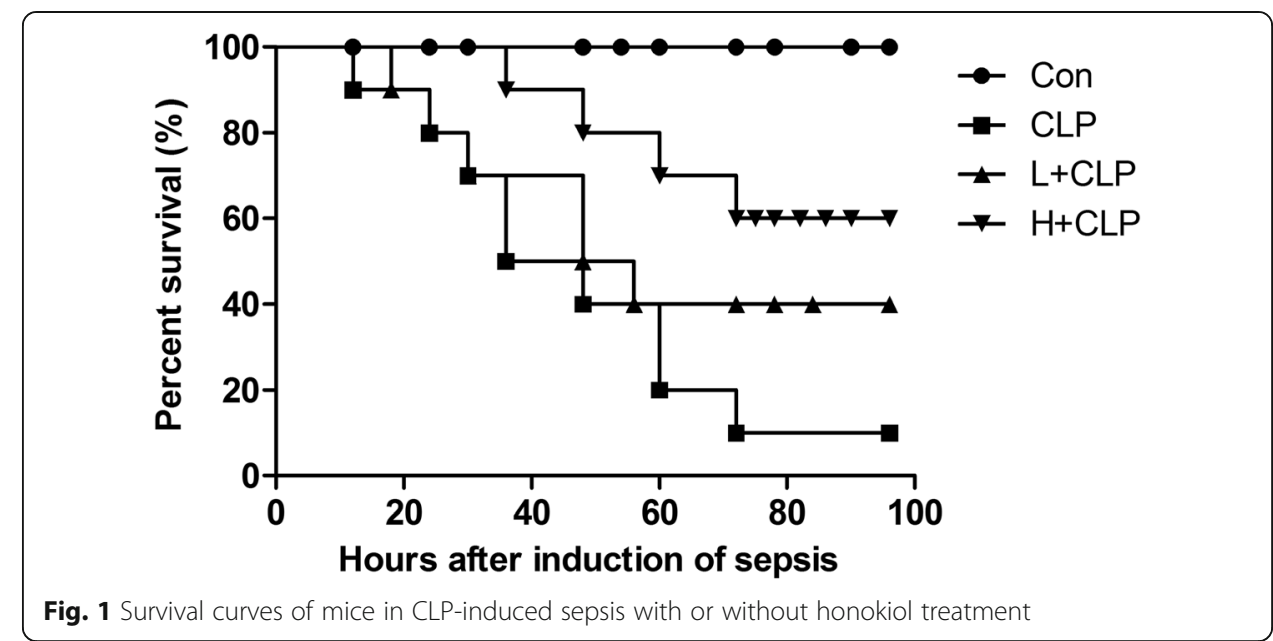

Bacterial counts in septic mouse organs are inhibited after honokiol treatment

Bacterial counts in blood, kidney, liver and brain were measured after induction of sepsis with CLP treatment for $24 \mathrm{~h}$. The bacterial counts in blood, kidney, liver and brain were significantly higher in the CLP (Fig. 2) group than that of honokiol administration groups. These data suggest that honokiol exhibits strong bacteria-fighting ability in septic mice.

\section{Honokiol inhibits serum inflammatory cytokines in septic mice}

A dramatic increase in inflammatory cytokine levels is one of the major clinical features of sepsis [25]. In the present study, serum levels of TNF- $\alpha$, IL- 6 and IL-1 $\beta$ in septic mice and honokiol-treated septic mice were measured. As shown in Fig. 3a, serum levels of TNF- $\alpha$ were significantly increased in the CLP group as compared to the corresponding control group. However, honokiol administration markedly reversed CLP-induced up-regulation of TNF- $\alpha$ in septic mice. In addition, compared with the control group, the serum levels of IL- 6 and IL-1 $\beta$ were markedly induced in the CLP-induced (Fig. $3 \mathrm{~b}$ and c) septic mice model. However, honokiol administration significantly reduced IL- 6 and IL- $1 \beta$ in septic mice.

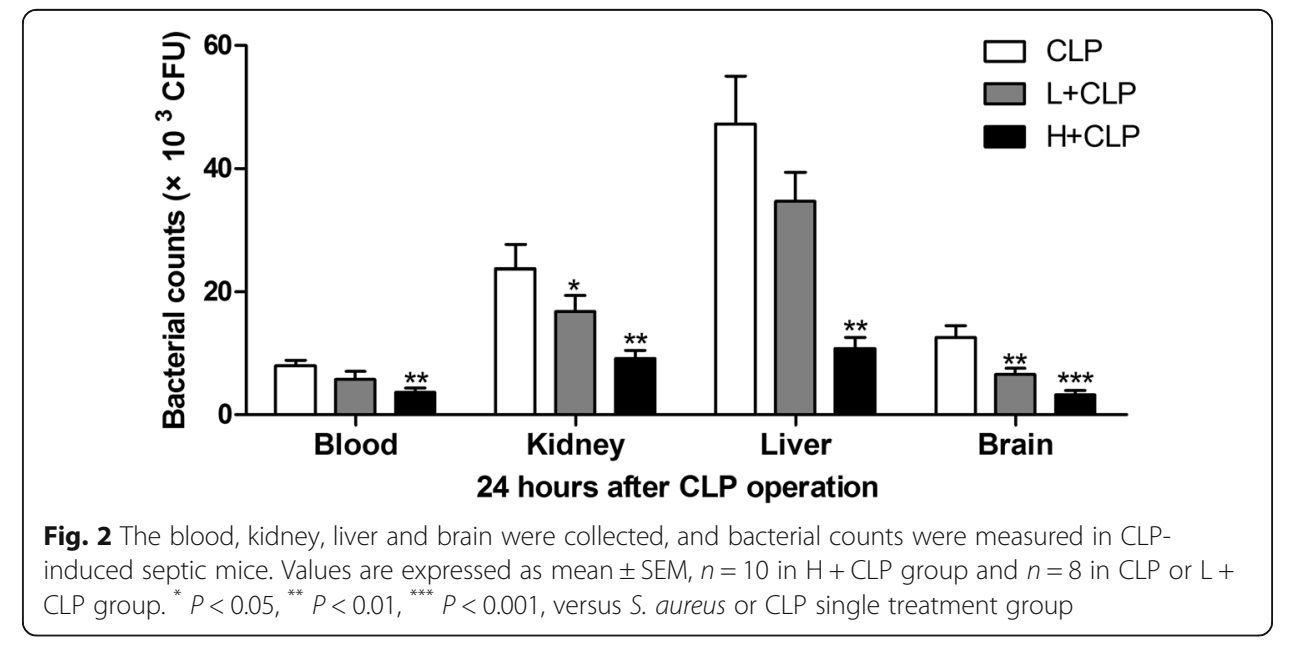




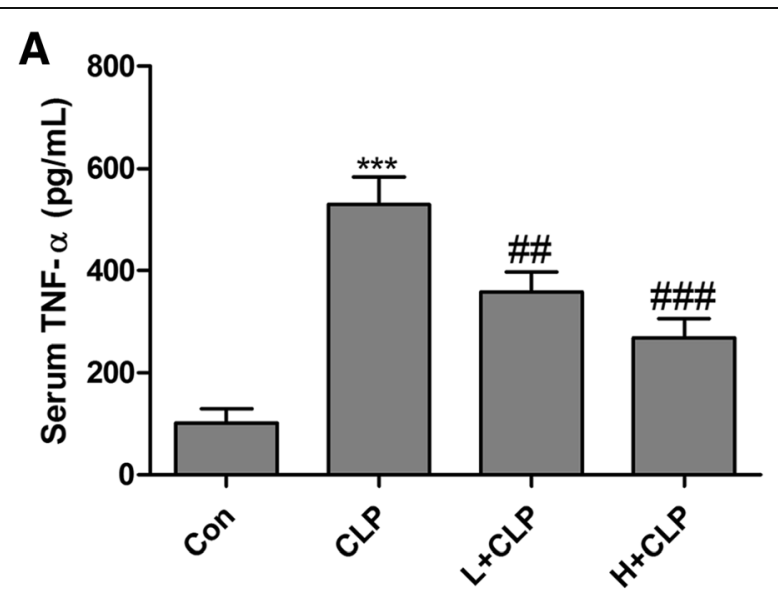

24 hours after CLP operation

B
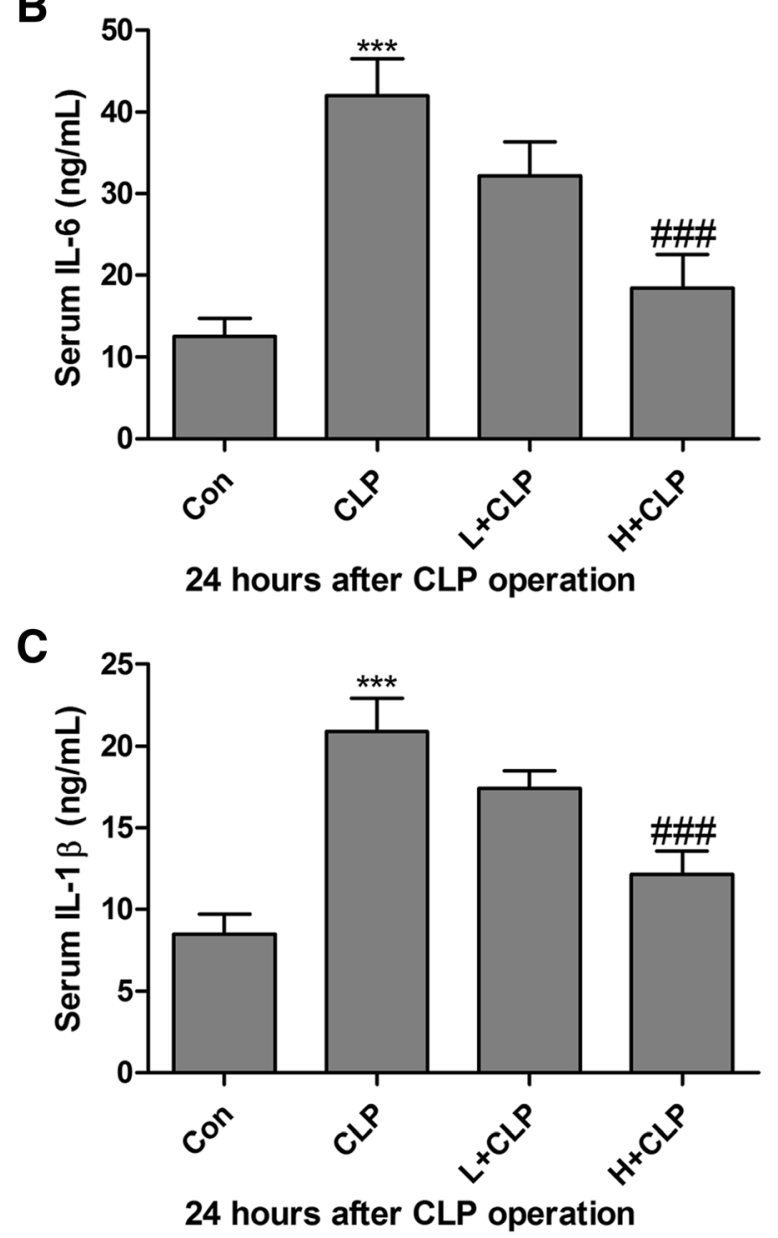

Fig. 3 Honokiol inhibits serum inflammatory cytokines in septic mice. Serum levels of TNF-a (a), IL-6 (b) and IL-1 $\beta$ (c) were detected using mouse bioactive ELISA assay in CLP-induced septic mice. Values are expressed as mean \pm SEM, $n=10$ in Con or $H+C L P$ group and $n=8$ in CLP or $L+C L P$ group. ${ }^{* * *} P<0.001$, versus control group; ${ }^{\# \#} P<0.01$ and ${ }^{\# \# \#} P<0.001$ versus CLP single treatment group

Honokiol ameliorates AKI in septic mice by targeting HO-1

To determine the role of honokiol in CLP-induced AKI in the septic mouse model, renal histological examination by PAS was implemented. The results indicated that a 
relatively intact structure of the kidney tissues was observed in normal mice. However, the CLP group showed significant glomerular and tubulointerstitial damage, which was restored in the presence of honokiol (Fig. 4a). These results show that honokiol significantly improves renal physiological structure and function in septic mice. To determine the effect of honokiol on HO-1 expression in CLP-induced AKI, the mRNA and protein expression levels of HO-1 were measured in the kidney of honokiol-treated septic mice. As shown in Fig. 4b and c, the levels of HO-1 mRNA and protein in the kidney were much lower in the CLP model group as compared to those in the control group. In contrast, the mRNA and protein expression levels of HO-1 in the kidney of septic mice were dramatically up-regulated with honokiol treatment. We also found that the apoptosis-related signaling pathway was activated in the kidney of septic mice, reflecting that the ratio of $\mathrm{Bcl}-2$ to $\mathrm{BAX}$ mRNA expression level was down-regulated in the

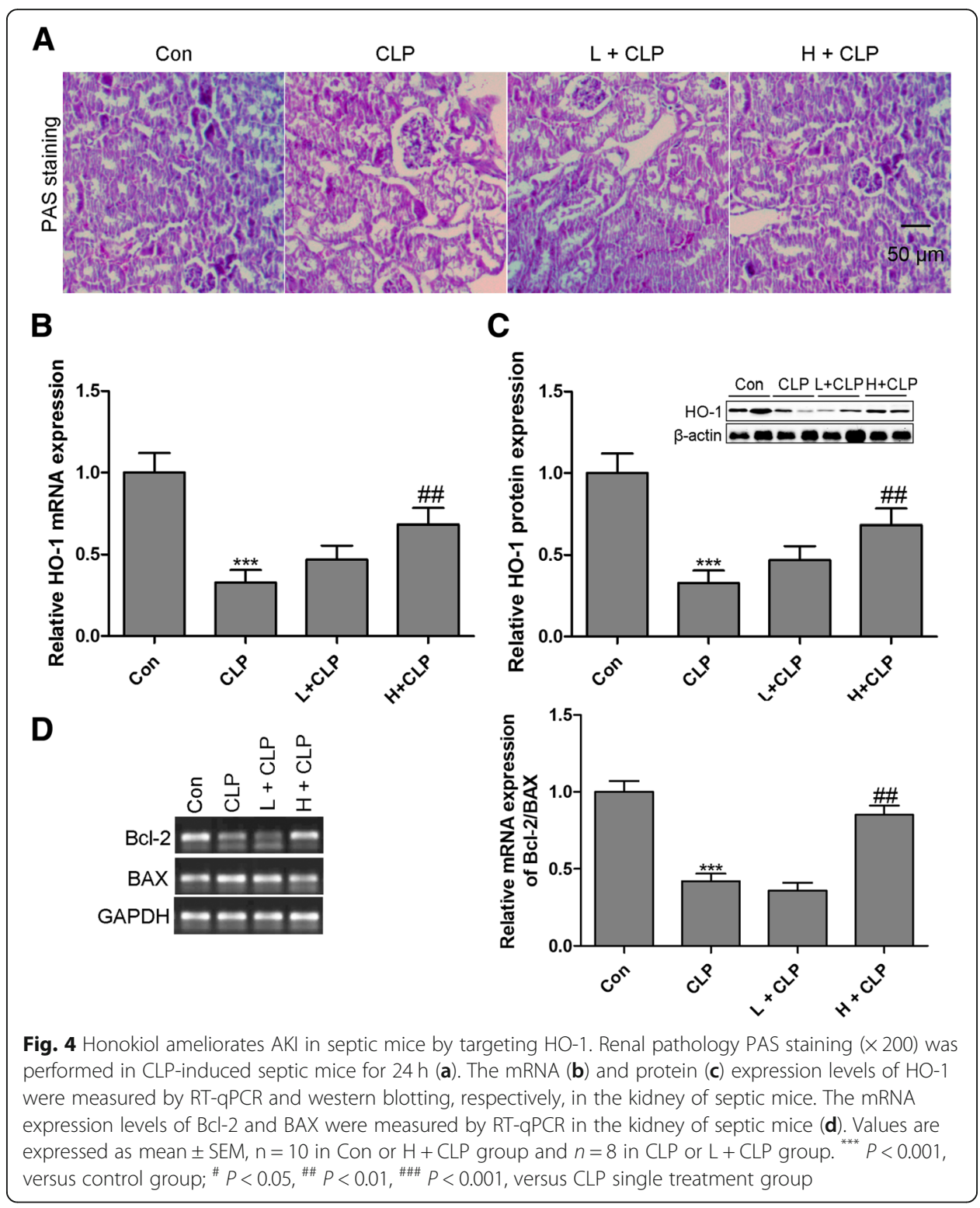


kidney of septic mice. However, CLP-induced apoptosis in the kidney was attenuated by honokiol treatment with high concentration (Fig. 4d).

\section{MiRNA expression in the kidney from septic mice}

To determine whether HO-1-related miRNAs were involved in sepsis-induced AKI, we used the online prediction software TargetScan (www.targetscan.org) and miRDB (http://www.mirdb.org/miRDB/) to identify potential miRNAs that could target HO-1. Using these approaches, 17 miRNAs (miR-7119-3p, miR-377-3p, miR-7053-5p, miR-3092-5p, miR-672-3p, miR-7231-5p, miR-6975-5p, miR-7005-5p, miR-8108, miR-343, miR-881-5p, miR-6919-5p, miR-7002-3p, miR-218-5p, miR-7026-3p, miR-134-5p and miR-7020-3p) were identified as candidate miRNAs. Among these miRNAs, 8 miRNAs were significantly up-regulated and 4 miRNAs were significantly down-regulated in the kidney from septic mice compared with that of the control group (Fig. 5a). In addition, the expression of 5 miRNAs showed no significant

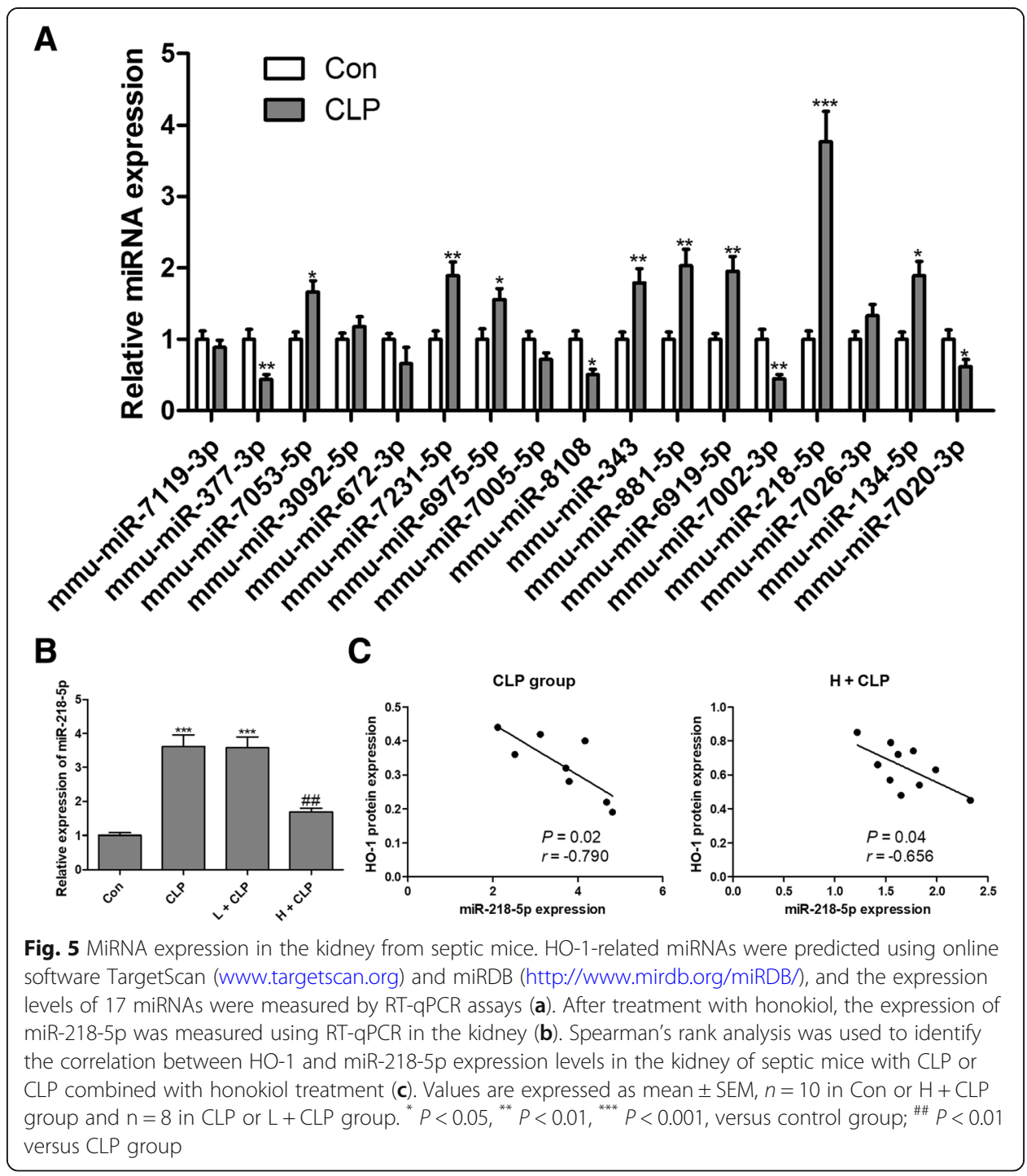


difference between the two groups (Fig. 5a). We found that the fold change of miR-218-5p was approximately 3.8-fold at the highest level. Therefore, we selected out miR-218-5p for further investigation. Intriguingly, CLP-induced up-regulation of miR-218-5p in the kidney of septic mice was significantly reduced by honokiol with high concentration (Fig. 5b). We also found a significant negative correlation between miR-218-5p and HO-1 protein expression in both septic mice (Fig. 5c) and septic mice with honokiol treatment at high concentration (Fig. 5c). These findings suggested that HO-1 and miR-218-5p might play reciprocal roles in the progression of CLP-induced AKI.

\section{HO-1 is a direct target of miR-218-5p}

The conserved binding sites between miR-218-5p and HO-1 were predicted using the online software TargetScan and miRDB, and the binding sites between miR-218-5p and HO-1 are shown in Fig. 6a. To confirm this prediction, a luciferase reporter assay was performed, and the results demonstrated that miR-218-5p mimics co-transfected with WT 3'-UTR of HO-1 significantly diminished the luciferase enzyme activity (Fig. 6b), while the luciferase enzyme activity showed no significant change in GMCs transfected with MT 3'-UTR of HO-1 (Fig. 6b). As shown in Fig. 6c and d, both mRNA and protein expression levels of HO-1 were dramatically reduced in GMCs transfected with miR-218-5p mimics compared with the control group. These findings showed that HO-1 was a direct target of miR-218-5p.

Honokiol blocks LPS-induced cell growth inhibition and apoptosis by targeting miR-2185p/HO-1

In honokiol-treated septic mice, sepsis-induced up-regulation of miR-218-5p in the kidney was markedly reversed by honokiol at the concentration of $10 \mathrm{mg} / \mathrm{kg}$ (Fig. 7a). We

A $\begin{array}{cc}\text { HO-1 (WT) } & \text { 5'-GUUCCCUCACCAAAAGCACAU-3 } \\ \text { II II IIII } \\ \text { mmu-miR-218-5p } & \text { 3'-UGUACCAAUCUAGUUCGUG }\end{array}$ HO-1 (MT) 5'-GUUCCCUCACCAACCAUCUGU-3'

B

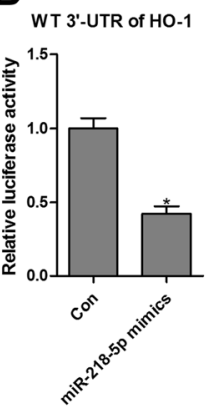

MT 3'-UTR of HO-1

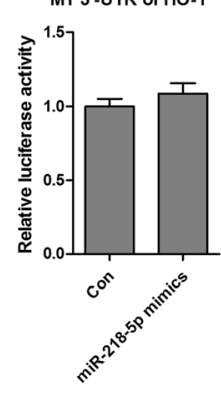

C

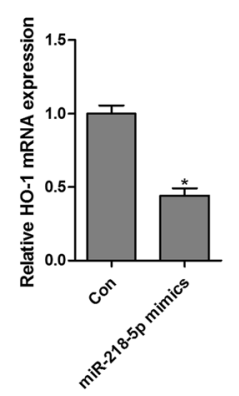

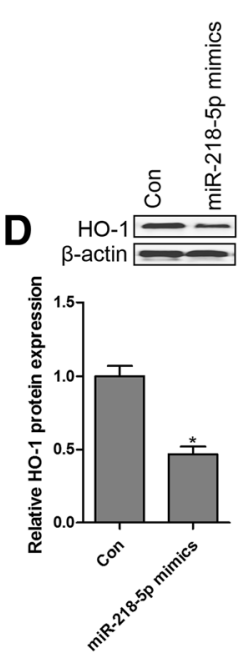

Fig. 6 HO-1 is a direct target of miR-218-5p. The conserved binding sites between miR-218-5p and HO-1 were predicted using online software TargetScan and miRDB (a), and the luciferase activity assay was performed to validate HO-1 as a direct target of miR-218-5p (b). After transfection with miR-218-5p mimics into GMCs, the mRNA (c) and protein (d) expression levels of HO-1 were measured by RT-qPCR and western blotting, respectively. Values are expressed as mean \pm SEM, $n=3$ in each group. ${ }^{*} P<0.05$ versus control group 
A

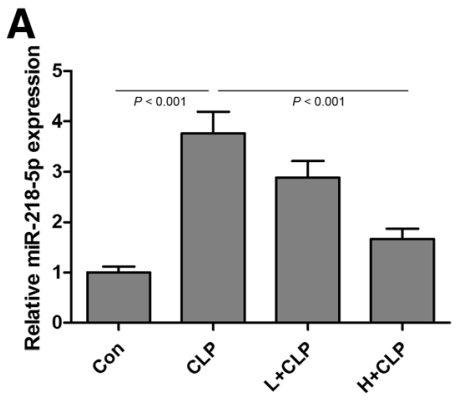

C

- Con

- LPS

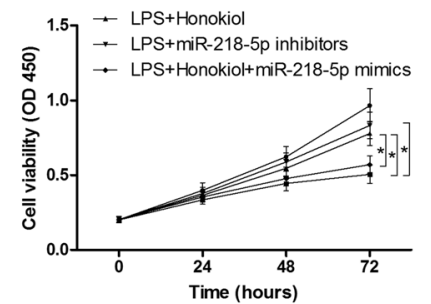

$\mathbf{E}$

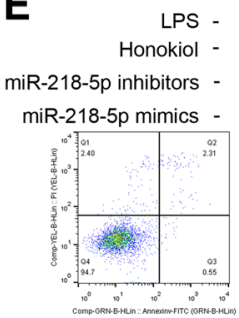

$\mathbf{F}$
B

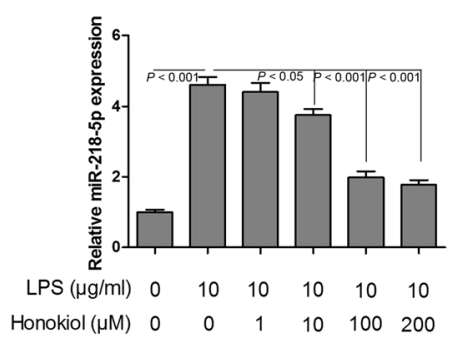

D

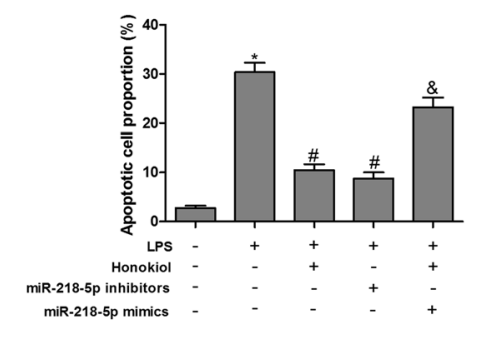

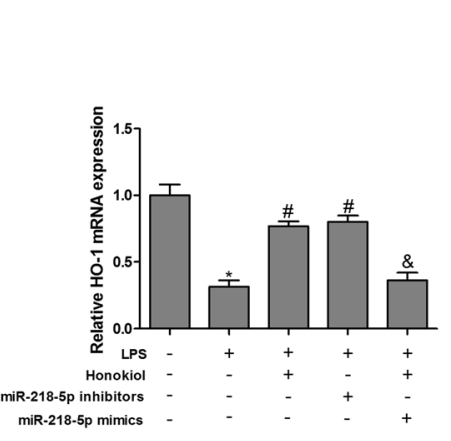
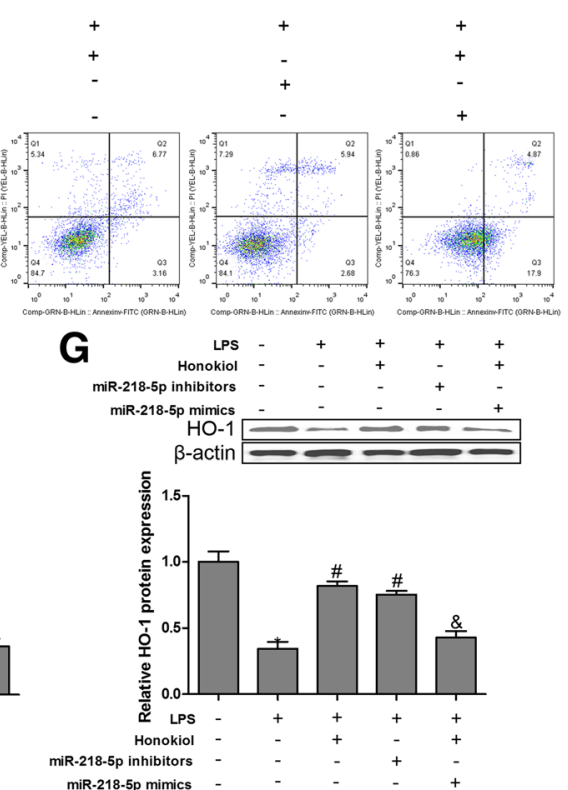

Fig. 7 Honokiol blocks LPS-induced cell growth inhibition and apoptosis by targeting miR-218-5p/HO-1. The expression levels of miR-218-5p were measured using RT-qPCR assays in the kidney from septic mice with or without honokiol treatment (a) and in LPS-stimulated GMCs with or without honokiol treatment (b). GMCs were exposed to different conditions, cell viability was measured by CCK-8 assay (c); cell apoptosis was performed by flow cytometry ( $\mathbf{d}$ and $\mathbf{e}$ ); the mRNA (f) and protein $(\mathbf{g})$ expression levels of HO-1 were measured by RT-qPCR and western blotting, respectively. Values are expressed as mean $\pm S E M, n=3$ in each group. ${ }^{*} P<0.05$ versus control group; ${ }^{\#} P<0.05$ versus LPS treated group; ${ }^{\&} P<0.05$ versus honokiol+ LPS treated group

also performed in vitro experiments to investigate the protective effect of honokiol on LPS-stimulated GMCs. First, we found that honokiol inhibited LPS-induced up-regulation of miR-218-5p in GMCs in a concentration-dependent manner (Fig. 7b). LPS-induced cell growth inhibition (Fig. 7c) and apoptosis (Fig. 7d and e) in GMCs were reversed by both honokiol and miR-218-5p inhibitor treatment, while miR-218-5p mimics neutralized the protective effect of honokiol on LPS-stimulated GMC injuries 
(Fig. 7c, d and e). Furthermore, our results revealed that both honokiol and miR-218-5p inhibitors elevated the mRNA and protein expression of $\mathrm{HO}-1$ in LPS-stimulated GMCs (Fig. $7 \mathrm{f}$ and g). However, overexpression of miR-218-5p reversed the up-regulation of $\mathrm{HO}-1$ mRNA and protein expression by honokiol in LPS-stimulated GMCs (Fig. $7 \mathrm{f}$ and g). These findings indicated that miR-218-5p/HO-1 signaling was crucial for LPS-induced cell growth inhibition and apoptosis in GMCs, and that honokiol could suppress LPS-induced cell growth inhibition and apoptosis in GMCs by regulating miR-218-5p/HO-1 signaling.

\section{Discussion}

In the present study, we demonstrated that honokiol had a beneficial effect on CLP-induced sepsis and significantly increased the survival in mice undergoing the CLP operation. Several inflammatory cytokines, such as TNF- $\alpha$, IL-6 and IL-1 $\beta$, were significantly inhibited in honokiol-treated septic mice as compared to the CLP single treatment group. Moreover, honokiol could markedly reverse CLP-induced AKI in septic mice. Importantly, the underlying mechanism revealed that HO-1 levels were significantly up-regulated and miR-218-5p levels were markedly down-regulated in honokiol-treated septic mice. Bioinformatics and experimental measurements revealed that HO-1 was a direct target of miR-218-5p. In vitro experiments showed that both honokiol and miR-218-5p inhibitors blocked LPS-induced cell growth inhibition and apoptosis in GMCs by increasing the expression of HO-1. These findings indicated that miR-218-5p/HO-1 signaling played an important role in sepsis-induced AKI and LPS-induced GMC dysfunction, and that honokiol could attenuate sepsis-induced AKI and LPS-induced GMC dysfunction by regulating miR-218-5p/HO-1 signaling.

Previous findings have demonstrated that honokiol is well tolerated by the host animal in therapeutically beneficial doses, and an acute toxicity study indicated that the $\mathrm{LD}_{50}$ of honokiol is $98 \mathrm{mg} / \mathrm{kg}$ administered intraperitoneally in mice [5]. The concentration of honokiol in our study was less than $10 \mathrm{mg} / \mathrm{kg}$ in septic mice, which ensured drug safety. Honokiol shows cytotoxicity and antimicrobial activity in S. aureus [26-28]. In our study, the bacterial counts in blood, kidney, liver and brain were significantly higher in the CLP group than the honokiol administration groups. These data suggest that honokiol exhibits strong bacterial killing ability in septic mice. Honokiol has been shown to ameliorate survival in a sepsis-induced acute lung injury mouse model and inhibit CLP- or LPS-induced oxidative stress and inflammation in lung tissues [5]. In CLP-induced septic rats, honokiol protected against sepsis-induced AKI through the inhibition of oxidative stress and inflammatory cytokine production and NF- $\mathrm{KB}$ signaling [11]. However, the precise mechanisms underlying sepsis-induced AKI still remain to be fully elucidated.

HO-1 is the rate-limiting enzyme in the degradation of heme to iron, carbon monoxide and biliverdin [18, 29]. A growing body of evidence suggests that HO-1 is involved in anti-inflammatory, anti-oxidant, anti-apoptotic, anti-proliferative and immunomodulatory effects that protect diverse organs against injury, including AKI [13]. A variety of rodent models have provided substantial evidence to support the role of $\mathrm{HO}-1$ as a cytoprotective enzyme and its adaptive up-regulation after tissue injury [30]. In the AKI animal model, HO-1 mRNA is induced in the kidney as early as 3 to $6 \mathrm{~h}$ [31]. Genetically deficient $\mathrm{HO}-1$ or inhibition of $\mathrm{HO}-1$ activity with chemical drugs can accelerate kidney dysfunction and tubular injury [18], suggesting a protective role for HO-1 
expression in kidney tissues. In a unilateral ureter obstruction mouse model, overexpressed HO-1 prevents renal interstitial inflammation and fibrosis by reducing macrophage infiltration and preventing the activation of $\mathrm{Wnt} / \beta$-catenin signaling [32]. In the present study, we found that HO-1 was down-regulated in the kidneys following the CLP operation. Interestingly, down-regulated HO-1 was reversed in the kidneys of septic mice with honokiol administration. Our results indicated that HO-1 was involved in CLP-induced AKI in septic mice, and we also found that honokiol had a beneficial role in protecting against CLP-induced kidney injury by up-regulating HO-1 expression.

miR-218-5p as a post-transcriptional regulator repressed HO-1 expression in GMCs. Inhibition of miR-218-5p or honokiol administration blocked LPS-induced cell growth inhibition and apoptosis in GMCs by elevating HO-1 expression. Numerous studies have revealed that $\mathrm{HO}-1$ exerts anti-inflammatory and anti-apoptotic effects on LPS-induced tissue damage and cell dysfunction [33, 34]. Up-regulation of HO-1 serves an anti-apoptotic role in LPS-treated hepatic cells, endothelial cells and cardiomyocytes [34-36]. Our results showed that miR-218-5p inhibitors modulated the up-regulation of HO-1 expression in GMCs, leading to the attenuation of LPS-mediated apoptosis. A recent study reported that miR-218 accelerated high glucose-induced podocyte apoptosis by down-regulating HO-1 expression [37]. These results suggested that up-regulation of miR-218-5p expression might be closely associated with AKI and cell apoptosis.

Mesangial cell apoptosis is implicated in septic renal injury, and LPS stimulates the release of inflammatory cytokines, such as TNF- $\alpha$, IL-6 and IL-1 $\beta$ [38, 39]. LPS-stimulated mesangial cells are a convenient and reliable cell model to appraise the pathogenesis of sepsis-induced AKI in vitro. In addition, podocytes and proximal tubule epithelial cells are also recognized as cell models for AKI in vitro [40, 41]. In the present study, we selected only mesangial cells for research on the mechanism. However, we still believe that proximal tubule cells play a vital role in the pathogenesis of sepsis-induced AKI. Therefore, we intend to include proximal tubule cells in our future study.

In conclusion, our study demonstrated that honokiol could significantly ameliorate the pathological changes of kidney in septic mice induced by CLP and LPS-induced apoptosis in GMCs, and the underlying mechanism was mediated, at least partially, through the inhibition of miR-218-5p-mediated up-regulation of HO-1 expression.

\section{Additional file}

Additional file 1: Table S1. Primers for RT-qPCR. (DOCX $14 \mathrm{~kb}$ )

\footnotetext{
Abbreviations

3'-UTRs: 3'-untranslated regions; AKI: Acute kidney injury; CLP: Cecal ligation and puncture; GAPDH: Glyceraldehyde 3phosphate dehydrogenase; GMCs: Glomerular mesangial cells; GSI: Glomerulosclerosis index; HO-1: Heme oxygenase-1; ICUs: Intensive care units; PAS: Periodic acid-Schiff; TIS: Tubulointerstitial score
}

Acknowledgements

We give thanks to the Department of Critical Care Medicine and Department of Neurology, Tianjin Huanhu Hospital (Tianjin, China) for providing technical support. 
Availability of data and materials

All data are contained in the article.

\section{Authors' contributions}

Study design: TZ and $L X$; literature research, data acquisition and data analysis: TZ and $L X$; manuscript preparation and manuscript editing: TZ and LX; manuscript review: TZ and LX; cell experiments: $T Z$ and $L X$; histomorphometric measurement: TZ and LX; final approval of the version to be published: $T Z$ and $L X$.

\section{Ethics approval and consent to participate}

This study was permitted by the Ethics Committee of Tianjin Huanhu Hospital, Tianjin, P. R. China on January 9th in 2017 (approval number: C2017A0116).

\section{Consent for publication}

Not applicable.

\section{Competing interests}

The authors declare that they have no competing interests.

\section{Publisher's Note}

Springer Nature remains neutral with regard to jurisdictional claims in published maps and institutional affiliations.

\section{Author details}

'Department of of Intensive Care Unit, Tianjin Huanhu Hospital, No. 6 Jizhao Road, Tianjin 300060, People's Republic of China. ${ }^{2}$ Department of Neurology, Tianjin Huanhu Hospital, Tianjin 300060, People's Republic of China.

Received: 9 November 2018 Accepted: 13 February 2019

Published online: 22 February 2019

\section{References}

1. Zarjou A, Agarwal A. Sepsis and acute kidney injury. J Am Soc Nephrol. 2011;22:999-1006.

2. Uchino S, Kellum JA, Bellomo R, Doig GS, Morimatsu H, Morgera S, Schetz M, Tan I, Bouman C, Macedo E, Gibney N, Tolwani A, Ronco C. Acute renal failure in critically ill patients: a multinational, multicenter study. JAMA. 2005;294:813-8.

3. Epstein L, Dantes R, Magill S, Fiore A. Varying estimates of Sepsis mortality using death certificates and administrative codes - United States, 1999-2014. MMWR Morb Mortal Wkly Rep. 2016;65:342-5.

4. Pillai VB, Samant S, Sundaresan NR, Raghuraman H, Kim G, Bonner MY, Arbiser JL, Walker DI, Jones DP, Gius D, Gupta MP. Honokiol blocks and reverses cardiac hypertrophy in mice by activating mitochondrial Sirt3. Nat Commun. 2015;6: 6656

5. Weng Tl, Wu HY, Kuo CW, Liu SH. Honokiol rescues sepsis-associated acute lung injury and lethality via the inhibition of oxidative stress and inflammation. Intensive Care Med. 2011;37:533-41.

6. Chiang CK, Sheu ML, Hung KY, Wu KD, Liu SH. Honokiol, a small molecular weight natural product, alleviates experimental mesangial proliferative glomerulonephritis. Kidney Int. 2006;70:682-9.

7. Wu F, Zhang W, Li L, Zheng F, Shao X, Zhou J, Li H. Inhibitory effects of honokiol on lipopolysaccharide-induced cellular responses and signaling events in human renal mesangial cells. Eur J Pharmacol. 2011;654:117-21.

8. Wu JP, Zhang W, Wu F, Zhao Y, Cheng LF, Xie JJ, Yao HP. Honokiol: an effective inhibitor of high-glucose-induced upregulation of inflammatory cytokine production in human renal mesangial cells. Inflamm Res. 2010;59:1073-9.

9. Chiang CK, Sheu ML, Lin YW, Wu CT, Yang CC, Chen MW, Hung KY, Wu KD, Liu SH. Honokiol ameliorates renal fibrosis by inhibiting extracellular matrix and pro-inflammatory factors in vivo and in vitro. Br J Pharmacol. 2011;163:586-97.

10. Yu Y, Li M, Su N, Zhang Z, Zhao H, Yu H, Xu Y. Honokiol protects against renal ischemia/reperfusion injury via the suppression of oxidative stress, iNOS, inflammation and STAT3 in rats. Mol Med Rep. 2016;13:1353-60.

11. Li N, Xie H, Li L, Wang J, Fang M, Yang N, Lin H. Effects of honokiol on sepsis-induced acute kidney injury in an experimental model of sepsis in rats. Inflammation. 2014;37:1191-9.

12. Bolisetty S, Zarjou A, Agarwal A. Heme oxygenase 1 as a therapeutic target in acute kidney injury. Am J Kidney Dis. 2017:69:531-45.

13. Nath KA. Heme oxygenase-1 and acute kidney injury. Curr Opin Nephrol Hypertens. 2014;23:17-24.

14. Shimizu H, Takahashi T, Suzuki T, Yamasaki A, Fujiwara T, Odaka Y, Hirakawa M, Fujita H, Akagi R. Protective effect of heme oxygenase induction in ischemic acute renal failure. Crit Care Med. 2000;28:809-17.

15. Holzen JP, August C, Bahde R, Minin E, Lang D, Heidenreich S, Dietl KH, Spiegel HU. Influence of heme oxygenase-1 on microcirculation after kidney transplantation. J Surg Res. 2008;148:126-35.

16. Pittock ST, Norby SM, Grande JP, Croatt AJ, Bren GD, Badley AD, Caplice NM, Griffin MD, Nath KA. MCP-1 is up-regulated in unstressed and stressed HO-1 knockout mice: pathophysiologic correlates. Kidney Int. 2005;68:611-22.

17. Bolisetty S, Zarjou A, Hull TD, Traylor AM, Perianayagam A, Joseph R, Kamal Al, Arosio P, Soares MP, Jeney V, Balla J, George JF, Agarwal A. Macrophage and epithelial cell H-ferritin expression regulates renal inflammation. Kidney Int. 2015;88:95-108.

18. Bolisetty S, Traylor AM, Kim J, Joseph R, Ricart K, Landar A, Agarwal A. Heme oxygenase-1 inhibits renal tubular macroautophagy in acute kidney injury. J Am Soc Nephrol. 2010;21:1702-12.

19. Bolisetty S, Traylor A, Zarjou A, Johnson MS, Benavides GA, Ricart K, Boddu R, Moore RD, Landar A, Barnes S, DarleyUsmar V, Agarwal A. Mitochondria-targeted heme oxygenase-1 decreases oxidative stress in renal epithelial cells. Am J Physiol Renal Physiol. 2013:305:F255-64.

20. Pang Y, Young CY, Yuan H. MicroRNAs and prostate cancer. Acta Biochim Biophys Sin Shanghai. 2010;42:363-9. 
21. Wang S, Zhang Z, Wang J, Miao H. MiR-107 induces TNF-alpha secretion in endothelial cells causing tubular cell injury in patients with septic acute kidney injury. Biochem Biophys Res Commun. 2017;483:45-51.

22. Li XY, Zhang YQ, Xu G, Li SH, Li H. miR-124/MCP-1 signaling pathway modulates the protective effect of itraconazole on acute kidney injury in a mouse model of disseminated candidiasis. Int J Mol Med. 2018;41:3468-76.

23. Wilson RL, Selvaraju V, Lakshmanan R, Thirunavukkarasu M, Campbell J, McFadden DW, Maulik N. Thioredoxin-1 attenuates sepsis-induced cardiomyopathy after cecal ligation and puncture in mice. J Surg Res. 2017;220:68-78

24. Livak KJ, Schmittgen TD. Analysis of relative gene expression data using real-time quantitative PCR and the 2(-Delta Delta C(T)) method. Methods. 2001;25:402-8.

25. Guo Y, Li J, Hagstrom E, Ny T. Beneficial and detrimental effects of plasmin (ogen) during infection and sepsis in mice. PLoS One. 2011;6:e24774.

26. Park J, Lee J, Jung E, Park Y, Kim K, Park B, Jung K, Park E, Kim J, Park D. In vitro antibacterial and anti-inflammatory effects of honokiol and magnolol against Propionibacterium sp. Eur J Pharmacol. 2004;496:189-95.

27. Ho KY, Tsai CC, Chen CP, Huang JS, Lin CC. Antimicrobial activity of honokiol and magnolol isolated from Magnolia officinalis. Phytother Res. 2001;15:139-41.

28. Liu T, Pan Y, Lai R. New mechanism of magnolol and honokiol from Magnolia officinalis against Staphylococcus aureus. Nat Prod Commun. 2014;9:1307-9.

29. Sikorski EM, Hock T, Hill-Kapturczak N, Agarwal A. The story so far: molecular regulation of the heme oxygenase-1 gene in renal injury. Am J Physiol Renal Physiol. 2004;286:F425-41.

30. Wang G, Hamid T, Keith RJ, Zhou G, Partridge CR, Xiang X, Kingery JR, Lewis RK, Li Q, Rokosh DG, Ford R, Spinale FG, Riggs DW, Srivastava S, Bhatnagar A, Bolli R, Prabhu SD. Cardioprotective and antiapoptotic effects of heme oxygenase-1 in the failing heart. Circulation. 2010;121:1912-25.

31. Nath KA, Haggard JJ, Croatt AJ, Grande JP, Poss KD, Alam J. The indispensability of heme oxygenase-1 in protecting against acute heme protein-induced toxicity in vivo. Am J Pathol. 2000;156:1527-35.

32. Chen X, Wei SY, Li JS, Zhang QF, Wang YX, Zhao SL, Yu J, Wang C, Qin Y, Wei QJ, Lv GX, Li B. Overexpression of Heme Oxygenase-1 prevents renal interstitial inflammation and fibrosis induced by unilateral ureter obstruction. PLoS One. 2016;1::e0147084.

33. Jamal Uddin M, Joe Y, Kim SK, Oh Jeong S, Ryter SW, Pae HO, Chung HT. IRG1 induced by heme oxygenase-1/carbon monoxide inhibits LPS-mediated sepsis and pro-inflammatory cytokine production. Cell Mol Immunol. 2016;13:170-9.

34. Zhang ZH, Zhu W, Ren HZ, Zhao X, Wang S, Ma HC, Shi XL. Mesenchymal stem cells increase expression of heme oxygenase-1 leading to anti-inflammatory activity in treatment of acute liver failure. Stem Cell Res Ther. 2017;8:70

35. Chen H, Xie K, Han H, Li Y, Liu L, Yang T, Yu Y. Molecular hydrogen protects mice against polymicrobial sepsis by ameliorating endothelial dysfunction via an Nrf2/HO-1 signaling pathway. Int Immunopharmacol. 2015;28:643-54.

36. Shi Y, Jiang H, Yang X. PPARdelta activation protects H9c2 cardiomyoblasts from LPSinduced apoptosis through the heme oxygenase1mediated suppression of NFkappaB activation. Mol Med Rep. 2017;15:3775-80.

37. Yang H, Wang Q, Li S. MicroRNA-218 promotes high glucose-induced apoptosis in podocytes by targeting heme oxygenase-1. Biochem Biophys Res Commun. 2016;471:582-8.

38. Araujo M, Doi SQ, Palant CE, Nylen ES, Becker KL. Procalcitonin induced cytotoxicity and apoptosis in mesangial cells: implications for septic renal injury. Inflamm Res. 2013;62:887-94.

39. Li G, Fu J, Zhao Y, Ji K, Luan T, Zang B. Alpha-lipoic acid exerts anti-inflammatory effects on lipopolysaccharidestimulated rat mesangial cells via inhibition of nuclear factor kappa B (NF-kappaB) signaling pathway. Inflammation. 2015;38:510-9.

40. Xu MX, Wang M, Yang WW. Gold-quercetin nanoparticles prevent metabolic endotoxemia-induced kidney injury by regulating TLR4/NF-kappaB signaling and Nrf2 pathway in high fat diet fed mice. Int J Nanomedicine. 2017;12:327-45.

41. Shi M, Zeng X, Guo F, Huang R, Feng Y, Ma L. Anti-Inflammatory Pyranochalcone Derivative Attenuates LPS-Induced Acute Kidney Injury via Inhibiting TLR4/NF-kappaB Pathway. Molecules. 2017;22:pii: E1683.

\section{Ready to submit your research? Choose BMC and benefit from:}

- fast, convenient online submission

- thorough peer review by experienced researchers in your field

- rapid publication on acceptance

- support for research data, including large and complex data types

- gold Open Access which fosters wider collaboration and increased citations

- maximum visibility for your research: over 100M website views per year

At $\mathrm{BMC}$, research is always in progress.

Learn more biomedcentral.com/submissions 